\title{
La ecología que anida y palpita en las parábolas de Jesús
}

\author{
The ecology that nests and throbs in the parables of Jesus
}

\begin{abstract}
Resumen
Acercarse a las parábolas de Jesús en la óptica de la ecología representa una fascinante experiencia en estos tiempos en que la humanidad ha alcanzado niveles insospechados de inconciencia, indolencia e insensibilidad ante la vida de la Madre Tierra, la devastación de la selva amazónica, la crisis ambiental y la extinción de la vida en todas sus manifestaciones. Ellas nos evocan los imaginarios simbólicos y campesinos de Jesús de Nazaret, portadores de la esencia divina de la sabiduría y del Espíritu que palpita y anida en toda la Creación. Por tanto, hemos optado por el encuentro con cuatro parábolas que interrelacionan economía y ecología, Tierra y agricultura, riqueza y pobreza, usura y explotación, violencia y muerte. En cada una de ellas se perfilan los referentes centrales de la actual crisis ecológica que vivimos. Un sembrador y tres señores poderosos en la economía imperial romana del siglo I, a quienes la interpretación alegórica ha identificado con el Dios de Jesús, nos sacuden y remueven nuestros esquemas mentales para hallar otras vetas de interpretación crítica, alternativa y ecológica que sintonicen con el querer de Dios, el actuar de Jesús y los valores del Reino de Dios.
\end{abstract}

Palabras-clave: Tierra; economía; crisis ambiental; parábolas; Amazonía.

\begin{abstract}
Approaching the parables of Jesus in the perspective of ecology represents a fascinating experience. Nowadays, when humanity has reached unsuspected levels of unconsciousness, indolence and insensitivity to the life of Mother Earth: the devastation of the Amazon rainforest, the environmental crisis, and the extinction of life in all its manifestations; the parables evoke the symbolic and imaginary of Jesus of Nazareth, the peasant; bearer of the divine essence of wisdom and of the Spirit that throbs and nests throughout the Creation. So, we have opted for the encounter with four parables that interrelate economy and ecology, Earth and agriculture, wealth and

\footnotetext{
${ }^{1}$ Magister en Ciencias Bíblicas por la Universidad Bíblica Latinoamericana de Costa Rica. Profesor e investigador de Nuevo Testamento y tutor de trabajos de grado de la Especialización en Estudios Bíblicos de la Fundación Universitaria Claretiana de Colombia. Miembro fundador del Colectivo Ecuménico de Biblistas - CEDEBI de Colombia. balveralozco@gmail.com.
} 
poverty, usury and exploitation, violence and death. In each of them, the central referents of the current ecological crisis that we live in, are outlined. A sower and three powerful lords in the Roman imperial economy of the 1st century, who have been identified with the God of Jesus by the allegorical interpretation, shake and remove our mental schemes to find other streaks of critical, alternative and ecological interpretation, that tune into the wanting of God, the act of Jesus, and the values of God's Kingdom.

Key-words: Earth; economy; environmental crisis; parables; Amazonia.

\section{Introducción}

Las parábolas de Jesús han gozado de una aceptación y admiración muy grandes por parte del pueblo católico, protestante y cristiano. Sus narraciones nos han cautivado desde diversas ópticas y sus interpretaciones se nos han arraigado de manera tan profunda, tanto como las mismas parábolas, que no advertimos las tramas de conflictividad social, política, económica e ideológica que laten a su interior. Las interpretaciones alegóricas nos zambullen en las dimensiones moralistas, religiosas, intimistas e individualistas, que derivan incluso de las mismas versiones canónicas de los textos bíblicos y de la prédica de sacerdotes, religiosos y pastores de las iglesias.

Por tanto, se torna muy difícil, superar los imaginarios construidos sobre las interpretaciones alegóricas y proponer caminos nuevos y diferentes, que nos lleven a leer de manera histórica, crítica, liberadora, alternativa y ecológica el auténtico mensaje de las parábolas de Jesús. Uno de estos caminos es el que propone este número de RIBLA sobre ECOLOGÍA, el cual tropieza con ausencias manifiestas en las parábolas de los términos de uso corriente en nuestros contextos actuales como naturaleza, medio ambiente, cambio climático y ecología. En las parábolas encontramos un simbolismo del campo, del mundo rural en el que vivió Jesús de Nazaret, lo cual nos lleva a identificarlas como parábolas campesinas, pero también hay símbolos del mundo de la ciudad, lo cual hace posible las conexiones existenciales con nuestras vidas, independientemente de que exista una impronta ecológica. También, simultáneamente, encontramos otro simbolismo, proveniente de las alegorías que nos conecta con otras dimensiones existenciales, ya no vinculadas con el mensaje original de las parábolas, sino con las interpretaciones alegóricas.

Hemos de ser conscientes de las murallas que se interponen para poder hacer una relectura en perspectiva ecológica de las parábolas de Jesús. Por eso, este artículo pretende el abordaje a un grupo emblemático de parábolas de los evangelios sinópticos que proyectan diferentes tópicos acerca de la ecología y de la crisis ambiental, teniendo en cuenta que el 
término es de una acuñación reciente (Boff, 1993, p. 17²) y que no hay que buscar en las parábolas una forma explícita del mismo, pero sí los sentidos y horizontes hermenéuticos que nos iluminan nuevas interpretaciones de las parábolas en los tiempos actuales, enmarcados en la perspectiva del cuidado y la defensa de la Amazonía.

Se trata de un suculento aperitivo hermenéutico para quien se acerque con sentido crítico a la Sagrada Escritura; para quien se acerque con "imaginación sociológica" a escarbar en las profundidades de ese mundo simbólico de las parábolas; para quien se aproxime con sospecha, rebeldía y decisión de problematizar muros dogmáticos que han perdurado siglos y siglos en la interpretación de las parábolas de Jesús; para quien se aprovisione de sensibilidad y compasión con el cuidado y respecto de la Casa Común. Para los acercamientos no críticos e insensibles con la Madre Tierra, la naturaleza, el ambiente sano y el "Buen Vivir", podrá ser un desabrido aperitivo para abandonar en la mesa y desear un rápido traslado al recipiente de los residuos que van rumbo a los basureros de nuestros entornos bíblicos familiares, comunitarios, teológicos, académicos, religiosos, eclesiales y pastorales.

\section{La causa ecológica: un asunto de vida y muerte}

Estas líneas irrumpen desde el contexto de un país latinoamericano que ocupa el segundo lugar entre 22 países del mundo en asesinatos de líderes ambientales y defensores de la Tierra. Estos datos provienen de un reciente informe de una ONG inglesa, Global Witness, que lleva el registro del número de homicidios contra líderes ambientales y defensores de la Tierra (Calle, 2019, prr. 1). Las cifras son alarmantes para Colombia, que incluso supera las de Brasil. "En 2016, 37 de ellos fueron asesinados en Colombia, lo que nos puso en segundo lugar. Para 2017, con 24 muertes, quedamos en el tercer lugar y este año, la vergonzosa cifra se repite" (prr. 2). Claramente se observa un panorama muy difícil en el país para los liderazgos sociales y ecológicos, por lo que el tema ecológico y ambiental constituye un acierto muy significativo para RIBLA.

La periodista e investigadora peruana, Yvette Sierra Praeli, hizo público el artículo América Latina: la región con más asesinatos de defensores ambientales en el 2018, el pasado 30 de julio de 2019. Las cifras que nos proporciona sobre el panorama de la ecología en América Latina, fundamentadas en el informe de Global Witness, deben llevarnos a una reflexión profunda a lectores y lectoras de este No. de RIBLA sobre la Ecología, a teólogos,

\footnotetext{
${ }^{2}$ El término ecología fue acuñado en 1866 por el biólogo alemán Ernst Haeckel (1834-1919). Está compuesto de dos palabras griegas: oikos, que significa "casa", y logos, que quiere decir "reflexión o estudio". Así que, ecología quiere decir el estudio que se hace acerca de las condiciones y relaciones que forman el hábitat (casa) en su conjunto, así como de cada uno de los seres de la naturaleza (Boff, 1993) (Traducción del portugués por Amílcar Ulloa A.).
} 
teólogas y biblistas de todo el continente ${ }^{3}$. Las cifras corresponden a 2018 y dan cuenta de Colombia con 24 asesinatos, Brasil con 20, Guatemala con 16, México con 14, Honduras con 4, Venezuela con 3 y Chile con 2. Mientras hemos venido escribiendo este No. de RIBLA, perdieron la vida en América Latina 83 líderes ambientales ${ }^{4}$.

La reciente encíclica del Papa Francisco, Laudato SI, denuncia las diversas formas en que se está asesinando a la humanidad. "Existen formas de contaminación que afectan cotidianamente a las personas. La exposición a los contaminantes atmosféricos produce un amplio espectro de efectos sobre la salud, especialmente de los más pobres, provocando millones de muertes prematuras" (Francisco, 2019, p. 23). Y el listado de formas prosigue:

Se enferman, por ejemplo, a causa de la inhalación de elevados niveles de humo que procede de los combustibles que utilizan para cocinar o para calentarse. A ello se suma la contaminación que afecta a todos, debida al transporte, al humo de la industria, a los depósitos de sustancias que contribuyen a la acidificación del suelo y del agua, a los fertilizantes, insecticidas, fungicidas, controladores de malezas y agrotóxicos en general (Francisco, 2019, p. 23).

En este contexto irrumpe la realización del Sínodo Amazónico del 6 al 27 de octubre en Roma, cuyo título es: Amazonía: Nuevos caminos para la Iglesia y para una ecología integral. El documento preparatorio Instrumentum Laboris describe el mapa geográfico que comprende la Amazonía (parte de Brasil, Bolivia, Perú, Ecuador, Colombia, Venezuela, Guayana, Surinam y Guayana Francesa), cuya extensión es "de 7,8 millones de kilómetros cuadrados, en el corazón de América del Sur" (Asamblea Especial del Sínodo..., 2019, p. 12). El diagnóstico, según las comunidades consultadas en la Amazonía deja al descubierto la siguiente amenaza:

(a) la criminalización y asesinato de líderes y defensores del territorio; (b) apropiación y privatización de bienes de la naturaleza, como la misma agua; (c) concesiones madereras legales e ingreso de madereras ilegales; (d) caza y pesca predatorias, principalmente en ríos; (e) mega-proyectos: hidroeléctricas, concesiones forestales, tala para producir monocultivos, carreteras, ferrovías, proyectos mineros y petroleros; (f) contaminación ocasionada por toda la industria extractiva que produce problemas y enfermedades, sobre todo a los niños/as y jóvenes; $(\mathrm{g})$ narcotráfico; $(\mathrm{h})$ los

\footnotetext{
3 "Quienes defienden la tierra son amenazados y su compromiso por proteger ríos, bosques y otros recursos naturales se ha convertido en un peligro latente para sus vidas. Los asesinatos y amenazas se dan en todo el mundo, aunque en Latinoamérica se han presentado más de la mitad de los crímenes registrados durante 2018, según el último informe de Global Witness" (Sierra Praeli, prr. 1).

4 "En cuanto a las causas detrás de estos asesinatos, los conflictos asociados a la minería siguen ocupando el primer lugar. La agroindustria es la siguiente en la lista, mientras que la defensa de las fuentes de agua se ubica en el tercer lugar con 17 víctimas, 13 más de las registradas en el 2017" (prr. 5).
} 
consecuentes problemas sociales asociados a estas amenazas como alcoholismo, violencia contra la mujer, trabajo sexual, tráfico de personas, pérdida de su cultura originaria y de su identidad (idioma, prácticas espirituales y costumbres), y toda condición de pobreza a las que están condenados los pueblos de la Amazonía. (Asamblea Especial del Sínodo..., 2019, p. 16).

En consecuencia, vivimos en América Latina y el Caribe una devastación ecológica sin precedentes, contra la que advierte el Papa Francisco al manifestar que estas "situaciones provocan el gemido de la hermana tierra, que se une al gemido de los abandonados del mundo, con un clamor que nos reclama otro rumbo. Nunca hemos maltratado y lastimado nuestra casa común como en los últimos dos siglos" (Francisco, 2015, p. 51). Y este artículo busca llamar la atención sobre la toma de conciencia y la urgencia de una sensibilidad profunda sobre la Creación desde el acercamiento a algunas de las parábolas de Jesús en los evangelios sinópticos. También allí están presentes realidades de vida y muerte en torno a lo que acontecía en la vida cotidiana del pueblo.

\section{En el umbral de cuatro parábolas emblemáticas en los evan- gelios}

La región de Galilea presentaba una situación muy difícil en el siglo I, pues "los campesinos tenían que pagar el 25\% de la cosecha de cada producto de la tierra, además de ciertas cuotas para las tropas romanas" (Hoornaert, 1994, p. 58). En ese sentido puede darse un diálogo entre lo que allí sucedía y lo que vimos como amenazas de la región de la Amazonía, guardando las debidas distancias. Es verdad que las parábolas abordan diversas situaciones de la cotidianidad de la vida expresadas en formas concretas en los relatos de los milagros de Jesús, los cuales precisan ser leídos en relación con las denuncias de Jesús a través de las parábolas. Los cuadros del deterioro de la salud física, mental y espiritual, tienen estrecha vinculación con las realidades que subyacen en las narrativas parabólicas sobre la economía y la política.

Nuestra aproximación a las parábolas de Jesús toma en cuenta cuatro relatos representativos con respecto a nuestra intencionalidad hermenéutica, aunque en cada una de las parábolas podemos hallar aspectos relacionados con la ecología, pues su entorno vital (Sitz im Leben) fue el mundo rural y campesino de Galilea. En ese sentido, las parábolas de Jesús poseen un inmenso potencial hermenéutico de cara a la ecología en los tiempos de hoy, toda vez que constituyen un nexo profundo con la sabiduría campesina de Israel, reconociendo que su alegorización posterior domesticó su esencia histórica y profética. De ahí que sea fundamental reconocer el siguiente aporte de uno de los más reconocidos especialistas en parábolas, C. H. Dodd: "Estoy persuadido de que las parábolas, estudiadas de 
forma crítica, constituyen una de las principales fuentes para conocer la actividad histórica de Jesucristo, en especial por lo que se refiere a sus motivaciones y a sus consecuencias" (Dodd, 1974, p. 18).

Por su parte, Guido Mahecha manifiesta que las "parábolas tienen que brindar un mensaje que esté de acuerdo con las enseñanzas de Jesús":

En conclusión vamos a ver el papel del débil en la parábola y ver cómo la parábola puede ser un elemento de liberación para este grupo de personas. Por ello, afirmamos que una interpretación de las parábolas que justifique la discriminación, el abuso y el enriquecimiento basado en la usurpación de los bienes de otro no está de acuerdo con las enseñanzas de Jesús. (Mahecha, 2008, p. 13)

\subsection{La parábola del sembrador como expresión ecológica}

La encontramos en las tres versiones sinópticas de los evangelios (Mr 4, 1-9; Mt 13, 4-9; Lc 8, 5-8) y en la versión apócrifa del evangelio de Tomás. Se trata de uno de los textos más queridos y recordados en las iglesias, leído por siglos y siglos de una manera alegórica y espiritualizada. La alegoría comienza en Mc 4, 14, al intercambiarse los elementos de la siembra. En la parábola, el sembrador sembró la semilla al borde del camino; en la alegoría el sembrador sembró la palabra (mensaje), lo cual es diferente, pues desaparece el camino y los pájaros, para dar lugar a Satanás. La interpretación alegórica implanta una simbología diferente, colmándola de significados que se trasladan al campo de las actitudes, las cualidades y virtudes humanas, donde desaparece la dialéctica de la conflictividad social, política y económica que pesaba sobre la Tierra y el campesinado de Galilea.

Cuando nos aproximamos a la lectura de la parábola del sembrador en cualquiera de las versiones canónicas de los evangelios, incluso en la versión del texto apócrifo de Tomás, tenemos a la vista un teatro-mundo-ecológico, escenificado en cuatro cuadros o representaciones ecológicas, respecto de las cuales podemos caracterizar varios rasgos para una primera aproximación en perspectiva ecológica. El primer cuadro describe una acción de sembrar: una parte de semilla, la orilla del camino y la venida de unos pájaros que se la comieron. El segundo enuncia la acción de sembrar: otra parte de semilla, el terreno pedregoso, la ausencia de Tierra, el nacimiento prematuro, Tierra poco profunda, la salida del sol, el secamiento de la planta y la ausencia de raíz. El tercero muestra la acción de sembrar: otra parte de la semilla, la maleza, la asfixia de la semilla que no dio fruto. Y el cuarto cuadro da cuenta de la acción de sembrar: otra parte de la semilla, la Tierra buena, el desarrollo, el fruto y el rendimiento.

Nos interesa destacar algunos rasgos en la perspectiva ecológica de cara a la hermenéutica para los tiempos de hoy. El primero es la Tierra, presente cuatro veces en la parábola (vv. 1.5.8), en términos de proximidad 
con el mar (orilla), de carencia (poca Tierra), baja calidad (improductiva) y buena calidad (productiva). Este dato nos está mostrando en la Tierra el elemento transversal en las parábolas campesinas de Jesús. Por tanto, la clave fundamental para la vida, pues el fracaso o el éxito de la cosecha depende de su tenencia y de su buena calidad. Esta es la dialéctica de la parábola, la cual señala tres etapas de evidentes fracasos para llegar a una cuarta etapa de óptima productividad. Ahí podemos vislumbrar aspectos intertextuales muy interesantes para una perspectiva ecológica: la Tierra que mana leche y miel, la Tierra como identidad del pueblo de Israel, la Tierra como promesa, la Tierra como sueño y utopía. Y aunque la alegoría ratifica que lo "sembrado en la tierra buena se parece a aquellos que oyen el mensaje, lo reciben y dan fruto: uno treinta, otro sesenta y otro cien" (v. 20), sin embargo, para la perspectiva ecológica esta cuarta imagen de la parábola ofrece un potencial sorprendente en la óptica hermenéutica. Hemos de preguntarnos: ¿en manos de quién estaban las tierras buenas?, ¿cuál era el tipo de agricultura que daba estos altos rendimientos?, ¿qué tipo de contratación se imponía?

No obstante, la visión utópica de la Tierra buena, no nos puede hacer perder de vista la realidad mostrada en las tres primeras escenas, sobre las que Pedro Lima Vasconcellos (2001) levanta la pregunta: “ $i N o ~ p u e d e$ indicar realidades más precarias, como la dificultad de tener acceso a una tierra en mejores condiciones, más apropiada para plantar?" (p. 111). Luego señala: "Varias informaciones, inclusive del propio Nuevo Testamento, dan cuenta de que la situación en el campo era de extrema penuria. Habia grandes extensiones de tierra en manos de pocos, particularmente romanos o sus representantes" (p. 111). Y redondea, diciendo que las "aristocracias de Tiberíades y Jerusalén eran igualmente propietarias de muchas tierras, en general las más fértiles. La producción se orientaba de modo especial a la exportación" (p. 112). En igual sentido, Cañaveral Orozco (2012) apunta: "Es por ello que en tiempos de Jesús, el campesinado vivía una situación muy difícil, debido a la política de despojo de tierras por parte del Imperio romano y de los ricos de Jerusalén (saduceos)" (p. 196).

Un segundo elemento que es transversal a las parábolas en la perspectiva de la ecología está vinculado con la dialéctica de la conflictividad. Aunque la interpretación alegórica de la parábola del sembrador ha desterrado el elemento del conflicto social, en cada una de las escenas subyace un claro conflicto si se la interpreta en perspectiva histórica y no alegórica, incluso hasta en la última escena que desvanece cualquier sospecha de conflicto. Pedro Lima Vasconcellos plantea leer la parábola en esta dirección de la conflictividad: "Asi pues, nuestra parábola tematiza el trabajo campesino en un contexto de concentración de tierras, proceso éste que provoca cambios sensibles y dramáticos en la cotidianidad de las familias" (Vasconcellos, 2001, p. 112). Además, es muy iluminador el siguiente texto: 
Tal presentación del momento en que el trabajador obtiene al fin el resultado ansiado por su trabajo, y aún más de lo que pretendía, está en obvia contradicción con aquello que las familias campesinas realmente vivían... Si los tres primeros pasos del trabajo expuesto hacían una dramática presentación de la situación vivida, este último parece hablar de una realidad idealizada, diríamos utópica. Pero no por ello desligada de lo efectivamente experimentado. Este cuadro animador deja en el aire preguntas intrigantes e incómodas: ¿qué ocurre con la producción que con tanto costo se consigue? ¿Por qué trabajamos tanto y vivimos en penuria? Los impuestos y tributos que nos diezman la cosecha solo sirven para usurparnos el pan de cada día..." (Vasconcellos, 2001, p. 113).

El tercer elemento transversal a las parábolas en la óptica ecológica deriva de la enseñanza en parábolas. La enseñanza comienza en la orilla del lago, del lado de la Tierra, donde la gente permanecía en Tierra (v. 1). Marcos denomina el lago como mar, en tres veces, en un mismo versículo. La enseñanza prosigue desde el mar, el símbolo de poder del Imperio Romano, proyectada hacia quienes permanecen en la Tierra, junto a la orilla del mar. La simbología proviene de la vida y los ambientes rurales (semilla, sembrador, siembra, camino, pájaros, terrenos pedregosos, sol, raíz, maleza, fruto, etc.). La trama de la narración se teje sobre esta constelación de símbolos rurales a través de la que se articula una enseñanza diferente a la que imparte el Imperio Romano.

Finalmente, el cuarto elemento transversal está referido a la conciencia de los oyentes o destinatarios, elemento vinculante de la perspectiva ecológica, la cual demanda de una nueva conciencia crítica y ecológica (v. 9), que toma en cuenta las relaciones compasivas y amorosas del ser humano con todos los seres vivos con los que se interrelaciona. En la narración conecta el versículo 3 ("-¡Escuchen!") con el 9 ("-Quien tenga oídos para oír, que oiga!"). Ambas expresiones están en un tono imperativo, una especie de mandato ante una dramática situación que se ha de evidenciar en el relato de la parábola del sembrador. Esa situación interrelaciona las cuatro escenas de la parábola con la multitud que está en la orilla (del lado de la Tierra), con el mar y con Jesús que está sobre el mar. Es una toma de conciencia que debe llevar a una decisión ante el carácter denunciador y anunciador de la parábola y de la enseñanza de Jesús. Esta dimensión de la conciencia constituye uno de los pilares de la ecología en las parábolas de Jesús. Nuevamente, la alegoría jala para sí los niveles de conciencia, inclinándolos al lado moralizante, individual y espiritualizado de los oyentes. Corresponde, recobrar el llamado original de Jesús a la escucha en lo referente a los problemas y desafíos ecológicos que derivan de la Tierra y del sembrador. 


\subsection{La parábola del rico avaro como un campanazo a la devasta- ción ecológica}

Hemos puesto los ojos en esta parábola (Lc 12, 13-21) como una de las más expresivas en el evangelio de Lucas respecto de la acumulación de las riquezas y vecina inmediata de uno de los textos más emblemáticos sobre la ecología: Dios cuida de nosotros (Lc 12, 22-34). La antesala a la narración de la parábola enuncia uno de los versículos más impresionantes sobre la tragedia ecológica en el mundo actual: "-Tengan mucho cuidado con toda clase de avaricia; que aunque se nade en la abundancia, la vida no depende de las riquezas" (v. 15). Es interesante percibir que esta parábola no está en Marcos, aunque sí tiene resonancias en Mt 6, 19-20; Sant 4, 13-15 y Ap 3, 17-18. En ese sentido, articula una temática transversal más amplia sobre la avaricia, la cual está escandalosamente unida a la tragedia ecológica de nuestro tiempo. El contenido de la parábola da cuenta de campos cultivados (agricultura extensiva), a lo que se sigue la acumulación de cosechas y bienes (v. 18). Leif E. Vaage aborda el tema de la economía y la agricultura en Mateo en la perspectiva de una crítica a la acumulación de riquezas (Vaage, 1997, pp. 117.121-122). Y aunque el texto no lo dice explícitamente, lleva implícita la temática de la desigualdad que es inherente a la ecología en los tiempos actuales.

Para una aproximación ecológica, nuestra intencionalidad hermenéutica en este estudio bíblico de la ecología en las parábolas de Jesús, el texto nos ofrece una veta de seis verbos en el versículo 19 (tener, almacenar, descansar, comer, beber y divertir). Claramente se puede observar que sobre esto se estructura la sociedad de consumo, precisamente la que conjuga la avaricia, la ambición desmedida, la acumulación y la desigualdad. La parábola, vista en perspectiva ecológica, puede constituir el centro y el corazón del capítulo 12 en el Evangelio de Lucas, así como la perspectiva programática y teológica del evangelista frente a la riqueza y la pobreza. Cuando reflexionamos sobre la economía neoliberal en los tiempos actuales y tomamos en cuenta la situación sobre la Amazonía a la luz de Laudato Si y del Sínodo Panamazónico, esta parábola adquiere una singular importancia. Aquí cobra sentido la siguiente afirmación: "El empresario tiende inevitablemente a transformarse en rentista y a dominar cada vez más a quienes sólo tienen su trabajo... El pasado devora el porvenir" (Piketty, 2014, p. 643).

El texto siguiente (vv. 22-34), constituye un núcleo fundamental en la enseñanza de Jesús a sus discípulos en la perspectiva ecológica, en continuidad con el contenido de la parábola, cuya centralidad se manifiesta así: "Porque la vida es más importante que el alimento, y el cuerpo más que el vestido" (v. 23). Tales versículos expresan una crítica frontal al hombre rico de la parábola y a sus acciones por atesorar y acumular. Los cuervos son puestos como ejemplos frente a las siembras, las cosechas, las despensas y 
los graneros. Por tanto, la perspectiva del hombre rico, con todo su poderío económico, es derrumbada de un tajo en el final de la parábola: " «iTorpe! Esta misma noche morirás. ¿Para quién será todo lo que has almacenado?». Asíle sucede a quien atesora para si, en lugar de hacerse rico a los ojos de Dios" (v. 20).

En la intencionalidad hermenéutica con que nos estamos aproximando a las parábolas de Jesús resalta la dimensión del cuidado. En primer lugar, Jesús invita a cuidarse de la avaricia en todas sus expresiones. En segundo lugar, muestra el prototipo de rico avaro y, en tercer lugar, nos muestra a su Padre como el cuidador por excelencia, como también podemos leer en Deuteronomio 11, 12: "una tierra de la que cuida el Señor tu Dios y en la que tiene puestos sus ojos desde que empieza el año hasta que termi$n a^{\prime \prime}$. Por tanto, el cuidado de la vida y de la naturaleza proviene de Dios y tiene una dimensión divina y teológica. Leonardo Boff ha desarrollado esta temática sobre el cuidado esencial, advirtiendo que "fundamentalmente, configura un modo de ser, una relación nueva para con la realidad, la Tierra, la naturaleza y otro ser humano" (Boff, 2013, pp. 107-108).

En consecuencia, la ecología en las parábolas de Jesús tiene una viva expresión de transversalidad que interrelaciona ecología, economía y ecumenismo. Tanto la parábola del sembrador como la del rico avaro, presentan la dimensión económica en términos de tierras, siembras, cosechas, construcciones y acumulaciones. En igual perspectiva se ubican la de los viñadores homicidas y los talentos. Por detrás de esas realidades hay que buscar otras realidades más ocultas y encubiertas que no aparecen en la superficie de las parábolas, pero que hay que escarbar profundamente para hallarlas. La conciencia y la sensibilidad por la ecología, nos desafía en esa dirección.

\subsection{La parábola de los talentos como el más llamativo manual de economía antiecológica}

En Colombia, lugar geográfico desde donde se escribe este artículo, la parábola ha encajado perfectamente en un país de terratenientes, despojadores y usurpadores de tierras a las comunidades indígenas, afrodescendientes y campesinas. Sin lugar a dudas, la manera como las iglesias interpretan la parábola de los talentos, contribuye de manera eficaz a una espiritualización del mensaje en favor de los grandes intereses de terratenientes y transnacionales que se abalanzan sobre las mejores tierras colombianas y latinoamericanas.

Esas interpretaciones han ocultado la dialéctica conflictiva que comporta la parábola por dentro. No tienen ningún problema en identificar al señor (kyrios) con Dios, con el Dios de Jesús, para más señas. Tampoco tienen problema en proponer como modelos a imitar a los dos primeros siervos que negociaron con los talentos y obtuvieron el máximo rendimiento 
de ganancias. Era y es lo normal. Y ante lo anormal, tampoco tuvieron dificultad en censurar y condenar históricamente al tercer siervo como el inútil, el holgazán, el malo de la película, el que no produjo ganancias y utilidades al señor. Ningún asomo de chispa crítica para reconocer que el señor, identificado con el Dios de Jesús, era un usurero, un socio de los bancos, un captador de intereses, un depredador de la naturaleza y de la vida de sus sirvientes que no le producían utilidades. Y mucho menos, la "imaginación sociológica" pudo llegar a percibir cómo era que el señor se enriquecía, como procedía con sus deudores y cómo tenía sus fuerzas represivas para despojarlos y castigarlos. Para quienes les pueda interesar esta perspectiva de leer la parábola a contravía, a contracorriente, en modo alternativo, pueden leer el libro (Siervos, talentos, usuras y resistencias. El campesino que complicó la parábola de los talentos) (Cañaveral Orozco, 2015).

La primera pista en perspectiva ecológica la encontramos en el versículo 18: "Pero el que había recibido uno solo, fue, hizo un hoyo en la tierra y escondió el dinero de su señor". La Tierra es nombrada en dos veces en la parábola (vv. 18 y 25), como el lugar donde siervo, talento y Tierra se encuentran. El siervo cava el hueco en la Tierra para esconder el talento, interrumpiendo su ciclo de la ganancia, bajo la presión del miedo que siente ante su señor. La segunda pista se halla en los versículos 24 y 25: " "Señor, sé que eres hombre duro, que cosechas donde no sembraste y recoges donde no esparciste; tuve miedo y escondí tu talento en la tierra; aquí tienes lo tuyo»".

Los vínculos con la perspectiva ecológica los aporta el tercer siervo al relatar lo que hizo con la poderosa moneda (talento) que recibió del señor y al denunciar la manera como el señor se hacía rico. Si observamos con cuidado, podemos ver que las tres parábolas aluden a una economía agrícola extensiva, para la exportación, la cual tiene que ver con despojos de Tierra a los campesinos, pago de impuestos, créditos de bancos, transacciones comerciales y negocios a gran escala, guardando las proporciones de los tiempos de allá con los actuales. La agricultura extensiva posibilitaba el enriquecimiento de los señores, mientras la agricultura familiar y comunal a duras penas sobrevivía. El tercer siervo parece haber llegado a no ser parte de aquella agricultura comercial y denuncia al señor y a sus mecanismos de represión, pero es claro que tiene un vínculo con la Tierra y la naturaleza, lo cual es muy importante para el horizonte ecológico. Evidencia un nivel de conciencia frente a lo que sucede en dirección de lo que ya vimos en la parábola del sembrador acerca de aquella consigna: " $\mathrm{El}$ que tenga oídos para oír que oiga". Y ese nivel de conciencia es reprimido por el señor, quien ordena: "Y a este criado inútil arrójenlo fuera a la oscuridad. Alli llorará y le rechinarán los dientes" (v. 30). Pero el no tenerlo, es descaradamente premiado en el primer siervo y abusivamente amenazador para todo aquel que obre y actúe como el tercer siervo: "Por eso quitenle el talento y dénselo al que tiene diez. Porque a todo el que tiene se le dará y tendrá de sobra; 
pero al que no tiene, se le quitará incluso lo que tiene" (vv. 28-29).

Nuestras iglesias han interpretado la parábola como un bello manual del emprendimiento humano, un hermoso texto de los dones y talentos humanos que Dios nos confió, en nombre de lo cual se ha sustentado la teología de la prosperidad y se ha destrozado y aniquilado la misma Creación de Dios. Tal interpretación hace de la parábola un falso manual para que el ser humano sea ese "satán" devastador de la Tierra y la Casa Común como escribe Leonardo Boff (1993). No de otra manera puede comprenderse la manipulación de la Biblia para justificar la minería a cielo abierto, como podía leerse en el diario El Espectador: "El día que Dios respaldó la minería en Colombia" 5 .

No es la primera vez que el CEO de Eco Oro intenta persuadir a un auditorio con tesis de este calado. Hace unos días, durante el Congreso de Cinmipetrol en Cartagena, la figura del papa Francisco sirvió de fondo con este mismo objetivo. Los asistentes veían una foto del sumo pontífice acompañada de una supuesta declaración del mismo: "El día del juicio final ante Dios, nos contaremos entre los que enterraron el talento dado y no lo hicieron fructificar. No sólo en agricultura y ganadería, sino también en minería". (prr. 14)

\subsection{La parábola de los viñadores homicidas como un espejo de la violencia hoy}

La cuarta parábola, para esta aproximación ecológica, es un texto violento, de difícil interpretación (Mc 12, 1-12). Desde la misma versión canónica viene ya precedido de la interpretación alegórica, la cual dificulta su interpretación crítica, histórica y ecológica. La parábola conecta en su situación conflictiva y violenta con la viña de Nabot en 1 Re 21, 1-16. Allí tenemos claramente la perspectiva histórica como expresión del conflicto de la Tierra en el pueblo de Israel cuyo texto emblemático es el de la viña de Nabot. Un campesino tiene una viña que ha heredado de sus antepasados, paradójicamente al lado del palacio del rey, quien emplea todos los medios para apropiarse de ella. El campesino es seducido con ofertas de cambio y compra, pero no cede a las pretensiones del rey y es asesinado.

En la parábola del Evangelio de Marcos, se narra la trama conflictiva de una viña que posee unas características interesantes en sentido inverso a la viña de Nabot, pues en el texto del Antiguo Testamento la violencia es desencadenada desde los poderes políticos, económicos y religiosos de la monarquía contra la vida de Nabot, el legítimo heredero de la viña. Esa dialéctica conflictiva de allá es la misma que acontece hoy en

\footnotetext{
5 “Apoyado en diapositivas, Carrelo argumentó con versículos bíblicos la explotación minera. Y como si Bucaramanga recordara el paraíso, citó Génesis 2: 10-12: «Y salía de Edén un río para regar el huerto, y de allí se repartía en cuatro brazos. El nombre del uno era Pisón; éste es el que rodea toda la tierra de Havila, donde hay oro; y el oro de aquella tierra es bueno; hay allí también bedelio y ónice»" (Güesguán Serpa, 2013, prr. 13).
} 
los campos latinoamericanos, caribeños y amazónicos contra las comunidades indígenas, afrodescendientes, campesinas y contra nuestra Madre Tierra. Obviamente que el relato histórico es escrito desde la óptica del campesino Nabot. Por su parte, en la parábola de los "viñadores homicidas", según el texto canónico de Marcos, la viña es de un hombre, que la rodea con una cerca, construye un lugar para hacer el vino, edifica una torre, la arrenda a unos viñadores y se va de viaje. La trama violenta y asesina se sigue por cuenta de los labradores contra la vida de los siervos y el hijo del dueño de la viña. Claramente la narración se presenta en la óptica del propietario de la viña y en contra de los labradores.

Tras la narración se visibiliza una parte del conflicto, pero se oculta la otra parte, la cual hay que buscarla por medio de la reconstrucción sociohistórica, ya que el texto bíblico no ofrece posibilidades claras para hacerlo. Lo visible es un escenario violento en extremo donde los labradores tienen los instrumentos para reprimir y matar a la servidumbre del señor y hasta su propio hijo. La versión griega (La Cueva, 1990, p. 191-192) describe la muerte de varios siervos y del hijo, así como la de los labradores por parte del señor. En esa lógica, termina imponiéndose la fuerza del señor que acaba con los labradores y entrega la viña a otros. La alegoría ha desplazado la conflictividad a otros niveles, trasladando un conflicto de tierras, patronos y viñadores a otro de tipo religioso y teológico donde encaja perfectamente la interpretación en favor del señor y en contra de los labradores, aunque ambos se trenzaron en las acciones violentas y homicidas.

David Castillo (2019), haciendo un estudio de la parábola, plantea otro punto de vista:

Ahora, los viñadores del texto no son tan malvados cuando se lee la parábola desde la realidad del latifundio, la tenencia y renta de la tierra, la violencia para poseerla, y el discurso teológico que la legitima. Desde ahí la parábola es ventana a un mundo donde la desigualdad económica y social ha llegado a niveles escandalosos, y donde la tierra -fuente de sustento diario e identidad sociorreligiosa- es un elemento en violenta disputa. (Castillo, 2019, p. 3)

\section{Vetas ecológicas desde las parábolas de Jesús}

Las diversas tradiciones eclesiales han dado una significación muy grande a las parábolas de Jesús y han seguido, en su mayoría, una perspectiva acrítica de sus interpretaciones alegóricas, sin posibilitar o acoger otras miradas y sensibilidades que subyacen en las parábolas, dado el carácter polisémico de los textos bíblicos. La escogencia del subtítulo Vetas ecológicas tiene la intencionalidad de llevarnos a mundos desconocidos de las parábolas de Jesús y proyectar relecturas diferentes, críticas, atrevidas y alternativas a las que tradicionalmente nuestros oídos se han 
acostumbrado a escuchar toda la vida. Por esa senda nos han ayudado a transitar varias personas biblistas, aportándonos elementos para desentrañar aspectos ocultos en las parábolas de Jesús. Néstor Míguez nos dice:

Los relatos parabólicos, especialmente las parábolas bíblicas y particularmente las de Jesús, siempre encierran un elemento irreductiblemente paradójico. No son simples comparaciones didácticas, sino, por el contrario, enigmas construidos sobre la vida cotidiana, en la que irrumpe lo inesperado. Siempre hay una dimensión de misterio, una invitación a ir más allá de lo obvio, un sentido escondido que nunca podrá ser totalmente develado. (Míguez, 2004, pp. 144-145).

Ciertamente, el término "veta" proviene del latín «vitta», que significa cinta o venda, lo cual implica que hay que extraer de esa masa milenaria de la alegorización de las parábolas, las vetas y filones de ecología.

\subsection{La veta de la centralidad de la Tierra en el proyecto del Rei- no de Dios}

Sin duda alguna, la Tierra es el eje vertebral en las parábolas de Jesús de manera explícita e implícita, al punto crucial de que aunque su presencia sea simbólica en el Nuevo Testamento (Cañaveral, 2002, p. 23), adquiere un significado profundo en el proceso de crucifixión de Jesús. Milton Schwantes resalta esta condición en las siguientes palabras:

Al fin, nos encontramos en una sociedad, en la que la supervivencia y la riqueza son generadas por el trabajo en la tierra. Si hay conflicto, y si la ciudad y el Imperio proyectan controlar el campo, entonces la cuestión en disputa es la tierra y sus productos. Por tanto, la cuestión agraria está en el centro de la crucifixión de Jesús. La Teología de la cruz es fecundada en la lucha por la tierra. (Schwantes, 1989, p. 25).

Hay una coincidencia en los tres evangelios sinópticos en relación con el abordaje que hacen de la parábola del sembrador como un punto de inicio de la presentación parabólica de Jesús, donde la presencia directa de la Tierra, lo mismo que como terreno o como campos constituye lo que tratamos de expresar en el subtítulo y que se va extendiendo a las demás parábolas campesinas de Jesús (Mc 4, 1.5.8.16.20.26.28.31; Mt 13, 5.8.20.2324.27.31.36.38.44; 22, 5; 25, 18.25; Lc $8,6.13 .15 ; 12,16 ; 13,7 ; 14,18 ; 15,15.25)$. Es claro que en estos textos de parábolas percibimos la presencia de la Madre Tierra, por lo que desde aquí tenemos múltiples posibilidades hermenéuticas para la ecología. 


\subsection{La veta de una economía que apabulla la vida y la naturale- za en las parábolas}

Las cuatro parábolas que hemos tomado en consideración para este acercamiento ecológico a las parábolas de Jesús tienen en común su centralidad económica, aunque esta perspectiva ha sido nublada por la alegorización y espiritualización de su mensaje. La del sembrador, muestra en los capítulos de las tres versiones sinópticas una presencia de la Tierra como vértice de la economía romana, por lo que se podría sospechar que revela más el sentido de la parábola de la Tierra que la del sembrador. Tras de sí vemos que la Tierra está en manos de terratenientes, como lo escribió Hugo Echegaray (1980) y que ya fue suficientemente expuesto en páginas anteriores.

Por su parte, la del rico avaro, da cuenta de una economía cimentada en la agricultura extensiva que acumula las riquezas en pocas manos, como en continuidad con la del sembrador en la cuarta imagen, la de la Tierra buena. La Tierra buena era la que le habían arrebatado a los campesinos y la que podía generar ese volumen de riquezas. En esa misma dirección se pueden ubicar las parábolas de los talentos, la de los viñadores homicidas y la de los trabajadores de la viña (Mt 20, 1-16). Interesante que en las parábolas irrumpe el contexto de las siembras sin futuro, de los sembradores que fracasan en esos intentos por sobrevivir en medio de una economía y una agricultura a gran escala. Esto lo ilustra muy bien Néstor O. Míguez, al decir que muchas "veces los antiguos propietarios debian emplearse como asalariados u ofrecerse como siervos de los nuevos poseedores, $y$ trabajar la propia tierra para otros" (Míguez, 1995, p. 23). Ese podría ser el caso en la parábola del sembrador y en las demás.

Una especial atención recae en la de los talentos (Mt 25, 14-30), precisamente porque ella es una de las más llamativas en la línea de los emprendimientos humanos. Esta veta de la economía se manifiesta arrolladoramente en esta parábola, vista en perspectiva histórica y ecológica, pues la palabra talento se encuentra en 13 ocasiones de modo directo (Cañaveral Orozco, 2015, p. 44). La parábola puede considerarse un tratado de alta economía en el siglo I y no el bonito manual de los dones y capacidades que Dios concede al ser humano para los emprendimientos de toda clase, incluso los económicos. La alegorización de la parábola desfiguró su sentido histórico y hemos hecho de ella un perfecto manual para destrozar la vida de la Madre Tierra, la naturaleza y la vida humana.

El tercer siervo, a quien hemos estigmatizado como el personaje negativo de la parábola, ha venido a ser el encargado de proporcionarnos las claves para reconocer el espíritu perverso y diabólico que denuncia Jesús en la parábola. Cañaveral destaca el carácter rebelde y resistente del tercer siervo: 
Resulta muy interesante seguirle la pista al siervo que recibió un talento. El simbolismo empleado es sorprendentemente diferente al de los otros dos siervos. En primer lugar, fue y escavó en la Tierra y escondió el dinero de su señor. Con esta acción, renunció a entrar en la dinámica del comercio y de la ganancia de los otros dos siervos. Negó el apoyo al sistema económico vigente. ¿Acaso no se vislumbra ahí una postura de resistencia? ¿Por qué no llevó el talento a los banqueros para obtener la ganancia de intereses? ¿Podría intuirse la existencia de un conocimiento crítico de cómo funcionaban también los bancos de la época? (Cañaveral Orozco, 2015, p. 52)

La nota alta en la confrontación se percibe cuando el tercer siervo supera la experiencia humana del miedo y se enfrenta con el amo y le desnuda en su propia cara la forma como se ha hecho rico: " «Señor, sé que eres hombre duro, que cosechas donde no sembraste y recoges donde no esparciste; tuve miedo y escondi tu talento en tierra; aquí tienes lo tuyo» (vv. 24-25). Esa era la lógica del sistema económico romano, que funcionaba sobre la base de una sobreexplotación de la Tierra y de la obra esclava y jornalera. La biblista y teóloga Elsa Tamez apunta:

En lo que se refiere a la economía, el medio más importante de producción era la tierra... De manera que a principios de nuestra era encontramos una concentración de tierra en manos de pocos propietarios ricos no solo en Italia sino también en las provincias. Con este paso de una economía campesina a la de terrateniente, se da una tendencia a cambiar la cultura del cereal por formas de cultivo que producen más ganancia, como el vino y el olivo. Dicha política afectó a la gente pobre cuya alimentación era a base de cereal. (Tamez, 1993, pp. 68-69)

En la óptica crítica en que hemos abordado la parábola, escasamente inexplorada en esta veta de la economía, irrumpen nuevos y desafiantes sentidos hermenéuticos para la ecología, en cuanto critica al sistema económico romano allá y neoliberal hoy. El siervo asume una denuncia radical, profética, si se quiere suicida, contra la lógica usurera de las ganancias, al tiempo que es una postura ética contra el señor y contra los otros siervos: "aquí tienes lo tuyo", con cero ganancias. El siervo cortó o neutralizó todos los circuitos del sistema económico. Por eso recibe la calificación de ¡Criado miserable y perezoso! Y aunque el siervo había devuelto el talento, el señor lo sindica de haberse apropiado del dinero confiado. "Por eso quitenle el talento y dénselo al que tiene diez. Porque a todo el que tiene se le dará y tendrá de sobra; pero al que no tiene, se le quitará incluso lo que tiene" (vv. 28-29). Se trata de la desfiguración solapada que ejerce el sistema sobre los que no colaboran a sostenerlo. Y el desenlace de la parábola es dramático para el siervo valiente, rebelde y atrevido: "Y a este criado inútil arrójenlo fuera a la oscuridad. Alli llorará y le rechinarán los dientes". 


\subsection{La veta de una ausencia manifiesta en las parábolas aborda- das}

Hemos de reconocer que en las cuatro parábolas abordadas, salvo la del sembrador, se han escrito e interpretado desde la óptica de los señores ricos, para quienes el agua es un elemento más de los explotados. Llama la atención que en las versiones griegas de las cuatro parábolas no aparece el agua de modo directo, elemento vital para la agricultura, pero ignorado para los intereses económicos. Y llama la atención esta ausencia en las parábolas, cuando su presencia es notable en los demás pasajes de los evangelios. Alfredo Ferro Medina nos dice: "Si hablamos de teología del agua, en este caso concreto nuestra tarea consiste en descubrir la lógica de Dios sobre la realidad y la problemática del medio ambiente y del agua al servicio de todos los seres vivos" (Ferro Medina, 2005, p. 43). En tanto, Humberto Jiménez señala que la "voz agua aparece 582 veces en el Antiguo Testamento y cerca de 80 veces en el Nuevo. Pero no se agota alli el vocabulario referente al agua" (Jiménez, s. f., prr. 2). Sin embargo, en la parábola del sembrador aparece de modo indirecto referida al mar o al lago. La versión de Lucas, en su traducción da una referencia muy interesante a la Tierra que carecía de humedad, es decir, de agua $(8,6)$.

Esta invisibilidad es una buena veta hermenéutica para la ecología, punto en el que Marcelo de Barros alude a que el Pueblo de la Biblia tenía que definir su identidad en medio de pueblos que adoraban la naturaleza y hacían sacrificios humanos al sol, la luna, los ríos y las piedras. Por eso, en las leyes de la Biblia, el cuidado con la Tierra y el agua aparece de forma discreta y más implícita que de manera muy clara (Barros, 2003, p. 132). Y Marcelo llama la atención en los siguientes términos: "Hoy, debemos releer los textos biblicos a partir de la sensibilidad actual que es muy diferente de las cuestiones antiguas, a partir de las cuales los textos fueron escritos" (p. 132).

\subsection{La veta de una enseñanza crítica, liberadora, alternativa y ecológica}

Las parábolas constituyen el terreno de lo ideológico donde Jesús se sitúa de cara a la enseñanza de los valores del Reino de Dios y de los valores impuestos por la cultura romana. Ninguna otra parábola como la del sembrador se ocupa de responder a la población destinataria (discípulos y multitudes que lo seguían) en la extensión que lo hace. Muchos versículos son destinados a la explicación de la parábola a sus discípulos, hasta el punto de situarla como clave fundamental para entender las demás parábolas (v. 13), según la óptica del Evangelio de Marcos. Su amplia simbología del campo sobresale de principio a fin (el mar, la orilla, la barca, la siembra, la semilla, el camino, los pájaros, los terrenos rocosos, la Tierra, el sol, la raíz, la maleza, el fruto, la Tierra buena, el rendimiento y 
los oídos). Sin duda alguna, una extraordinaria constelación de imágenes ecológicas del campo.

Aníbal Cañaveral Orozco (2012) ha trazado unas líneas respecto de la enseñanza liberadora en la parábola del sembrador

El marco que antecede a la parábola es el de la enseñanza, presente en el inicio (4, 1-2) y en muchas otras partes del Evangelio (Mc 1, 21-22; 2, 13; 4 , $33 ; 6,2.6 ; 8,21.31 ; 9,31-32 ; 10,1 ; 11,17 ; 12,35.38 ;)$. Una enseñanza enraizada en la realidad que vivía la gente, la cual requería de abrir atentamente los oídos para oír, es decir, para saber oír (Cañaveral Orozco, 2012, pp. 190191).

El campesinado está ante dos enseñanzas: la de Jesús y la del imperio. La de Jesús es profundamente sensible al campo; la del imperio es una enseñanza impuesta, que abarca, que transforma usos y costumbres, que fomenta los valores de la cultura helenista. El campesino no está libre de recibir esa enseñanza del mundo urbanizado, helenizado y comercializado (Cañaveral Orozco, 2002, p. 118).

Los sentidos del oído y de la vista alcanzan una dimensión privilegiada en esta narración de la parábola, pues la primera nota de la enseñanza es: ¡Escuchen! (v. 3) y cierra con la misma referencia al escuchar: "-iQuien tenga oídos para oír, que oiga" (v. 9). Esta experiencia de ver y oír es referida a Isaías en un contexto de destrucción ecológica. Se trata de lo que precede a la explicación de la enseñanza en parábolas $(\mathrm{v}, 12)$ :

«Vete a decir a este pueblo: Por más que escuchen, no entenderán; por más que miren, no comprenderán. Endurece el corazón de este pueblo, tapa sus oídos, ciega sus ojos, no sea que sus ojos vean, sus oídos oigan, su corazón entienda, y se convierta y quede sano» (Is 6, 9-10).

En las parábolas hay un continuo llamado a la escucha, relacionada con la ecología. El profeta pregunta: «¿Hasta cuándo, Señor?». Es también la pregunta que podemos hacernos hoy desde una propuesta formativa en línea liberadora, alternativa y ecológica. Su respuesta continúa vigente: " "Hasta que las ciudades queden destruidas y despobladas, las casas deshabitadas, los campos desiertos». Porque el Señor alejará a los hombres y será inmensa la desolación del país" (Is 6, 11-12). Este es, pues, el contexto de intertextualidad que subyace a la expresión: "El que tenga oídos para oír, que oiga" y con el que se inicia la larga explicación de la parábola del sembrador a sus discípulos. Mateo detalla extensamente la explicación en referencia a Isaías, agregando una nota que omiten Marcos y Lucas: "Dichosos ustedes por lo que ven sus ojos y por lo que oyen sus oídos", mensaje que enaltece las capacidades de ver y oír, para concluir: "porque les aseguro que muchos profetas y justos desearon ver lo que ustedes ven y no lo vieron, $y$ oir lo que ustedes oyen $y$ no lo oyeron" (Mt 13, 16-17). 
Leonardo Boff destaca el sentido de la escucha en uno de sus escritos, palabras menos palabras más, la "ecología de la mente, también llamada ecología profunda, procura despertar en las personas su capacidad de escucha" (Boff, 2004, p.191). Y en uno de sus recientes libros hace un llamado a lo que denomina ecoeducación:

Concluyendo: los hijos e hijas de esta ecoeducación, que ha colaborado en la creación de un «modo sostenible de vida» (Carta de la Tierra), ciertamente serán muy diferentes de los actuales. Deberán sentirse profundamente unidos a la Madre Tierra, hermanados en todos los seres vivos, nuestros «parientes», preocupados y solícitos por todo cuanto existe y vive con una conciencia nueva, la conciencia planetaria, que nos hace percibir que vida, humanidad, Tierra y universo formamos una única, grande y compleja realidad (Boff, 2013, p. 174).

\subsection{La veta antiecológica del despojo de la vida y la dignidad humana en las parábolas}

De tiempo atrás se ha presentado una preocupación frente a varias expresiones que acompañan el epílogo de algunas de las parábolas y que en los estudios bíblicos se llega a decir que son anexos posteriores que no hacen parte de las narraciones originales. He aquí un registro de una de ellas: "Pues al que tenga se le dará, y al que no tenga se le quitará incluso lo que tiene" (Mc 4, 25; Mt 13, 12; 25, 28). Esta frase aparece como moraleja en algunas parábolas de Jesús y, en la mayoría de las veces, no levanta ninguna problematización. Por el contrario, es una sentencia certera para legitimar las interpretaciones alegóricas. Se trata de despojar a la persona, como en el caso de la parábola de los talentos, hasta de lo poco que tiene y echarla al lugar de la oscuridad. Eso acontece por cuenta del señor, del mismo que hemos confundido con el Dios de Jesús. Con razón que empresarios como los de las transnacionales de la minería en Colombia no tuviesen el menor escrúpulo ético para decir que en el juicio final, Dios nos iba a pedir cuentas por haber enterrado el talento y no haber apoyado la minería extractiva y la ganadería extensiva.

Hay ahí una enorme posibilidad hermenéutica para la ecología en los tiempos actuales. El sistema económico despoja a los pobres de lo poco que les queda para vivir y los expulsa a lugares de muerte. Así mismo, despoja a la Tierra de todas sus riquezas naturales y la convierte en desiertos invivibles, lugares de muerte. Se apropia del agua, de la que ya dijimos que está escasamente presente en las parábolas, despojando a poblaciones enteras de esta fuente para la vida. Y, finalmente, de manera violenta, despoja de la vida a quienes luchan por la defensa de la Tierra, el agua y el ambiente sano. Esto es lo que hay que desentrañar en la interpretación de las parábolas en perspectiva ecológica, arrebatándole a la alegoría todo el 
poder que ha tenido en alterar el sentido original e histórico de las parábolas.

En idéntico sentido, pasa con otra frase conclusiva: "Allí llorarán y les rechinarán los dientes", de notable presencia en el evangelio de Mateo $(13,50 ; 22,13 ; 25,30)$, sobre la que es escasa la investigación bíblica. José Rodríguez Rodríguez aporta luces importantes en su tesis doctoral ${ }^{6}$, indicando que el término skoto designa la "tiniebla", la "oscuridad" en primer lugar. Y por extensión "la oscuridad de la muerte", "la oscuridad de los infiernos", "la ceguera", "lo evanescente", "el infortunio", la "incertidumbre" (Rodríguez Rodríguez, 2013, p. 74).

Una relectura en perspectiva ecológica de las parábolas de Jesús nos llama a reconocer que los seres humanos nos hemos convertido en despojadores de las riquezas de la Madre Tierra, del campesinado, de los pueblos indígenas y las comunidades afrodescendientes y les hemos expulsado a estos lugares de la exclusión, el despojo y la muerte. La Madre Tierra, el agua, la naturaleza, los líderes y lideresas ambientales y sociales y los pueblos indígenas, negros y campesinos ocupan estos lugares que mencionan las parábolas, con ese distintivo: donde llorarán y les rechinarán los dientes.

\section{Conclusión}

Al concluir esta aproximación a las parábolas de Jesús en perspectiva ecológica, pudimos reconocer el inmenso potencial ecológico que guardan dentro de sus narrativas y su simbología campesina, rural y urbana. Urge, por tanto, recuperar su originalidad histórica y superar la influencia alegórica que las hizo distantes de los contextos dramáticos en que surgieron, domesticando y espiritualizando su mensaje liberador, profético, transgresor y subversivo para los tiempos de hoy. La ecología, como urgencia apremiante en el mundo de hoy, anida y palpita en cada una de sus expresiones simbólicas.

Las parábolas fueron el medio como Jesús comunicó su Buena Noticia a las multitudes, discípulos y discípulas que le seguían desde las aldeas y los poblados rurales de la región de Galilea. A través de ellas denunció las situaciones que vivían los campesinos y campesinas, víctimas de los abusos de los poderes que ejercían dominio sobre las poblaciones más vulnerables. Y por medio de ellas, anunció alternativas de cambio frente a la situación desesperanzadora que les agobiaba.

El presente artículo invita a leer e interpretar las parábolas en perspectiva ecológica y ambiental, reconociendo la centralidad de nuestra Madre Tierra y el desafío por alcanzar una economía ecológica que sustente

\footnotetext{
${ }^{6}$ Título: Luz y oscuridad en el Nuevo Testamento: estudio terminológico. Se trata de un texto de más de 400 páginas, donde el autor hace aportes muy interesantes sobre el significado de la luz, la oscuridad y las tinieblas.
} 
unas nuevas relaciones del ser humano con toda la Creación, cimentadas en el respeto, el amor, la integridad, el cuidado, la compasión, la ternura, la mística, la espiritualidad y el "Buen Vivir".

\section{Referencias bibliográficas}

ASAMBLEA ESPECIAL DEL SÍNODO DE LOS OBISPOS PARA LA REGIÓN PANAMAZÓNICA. (2019). Instrumentum Laboris. Amazonía: Nuevos caminos para la Iglesia y para una Ecología Integral. Bogotá, D.C.: Instituto Misionero Hijas de San Pablo.

BOFF, L. (1993). Ecologia - Mundialização - Espiritualidade. São Paulo (SP): Editora Ática S.A.

BOFF, L. (2004). Ecología: Grito da Terra Grito dos Pobres. Río de Janeiro: Editora Sextante.

BOFF, L. (2013). La sostenibilidad. Qué es y qué no es. Santander: Sal Terrae.

CALLE, H. (2019, 29 de julio). Colombia: el segundo país donde más asesinan líderes ambientales. El Espectador. Disponible en: https: / / www. elespectador.com/colombia2020/ pais/ colombia-el-segundo-pais-donde-mas-asesinan-lideres-ambientales-articulo-873431. Visitado el: 01 ago. 2019.

CAÑAVERAL OROZCO, A. (2002). El escarbar campesino en la Biblia. Quito: Centro Bíblico Verbo Divino.

CAÑAVERAL OROZCO, A. (2012). Andar en el encanto de la Palabra. Diálogo de saberes en Artifices, Entradas, Llaves y Claves. Bogotá: Ediciones Ántropos Ltda.

CANAVERAL OROZCO, A. (2015). Siervos, talentos, usuras y resistencias. El campesino que complicó la parábola de los talentos. Bogotá: Editorial Kimpres SAS.

CASTILLO, D. (2019). Del conflicto por la tierra a la parábola de la viña. El problema teológico de Mc 12, 1-12. Revista Theologica Xaveriana, Vol. 69, (188), pp. 1-12.

DE BARROS, M. (2003). O encanto da Água, segredo da Vida. En: Beozzo, J. O. (Organizador). ÁGUAÉ VIDA. Don de Deus e responsabilidade humana. São Paulo: Editorial PAULUS, pp. 109-142.

DODD, C. H. (1974). Las parábolas del reino. Madrid: Ediciones Cristiandad. ECHEGARAY, H. (1982). La práctica de Jesús. Salamanca: Ediciones Sígueme.

FERRO MEDINA, A. (2005). El agua, fuente bendita de vida. Aproximaciones a una teología, espiritualidad y pastoral del agua. Santiago de Cali: Instituto Mayor Campesino.

FRANCISCO, P. (2019). Carta encíclica Laudato SI. 3a. reimpresión. Bogotá: San Pablo. 
GÜESGUÁN SERPA, Ó. (2013, 29 de mayo). El día que Dios respaldó la minería en Colombia. El Espectador. Disponible en: https://www. elespectador.com/noticias / economia/ el-dia-dios-respaldo-mineria-colombia-articulo-424937. Visitado el: 02 ago. 2019.

HOORNAERT, E. (1994). El movimiento de Jesús. México, D.F.: Ediciones Dabar.

JIMÉNEZ, H. (s. f.) El agua en la Biblia. Servicio Biblico Latinoamericano. Disponible en: http:/ / servicioskoinonia.org/relat/190.htm. Visitado el: 19 ago. 2019.

LA CUEVA, F. (1984). Nuevo Testamento Interlíneal Griego-Español. Barcelona: Editorial Clie.

LIMA VASCONCELLOS, P. (2001). Sembrar... para la fiesta que viene después. Revista de Interpretación Biblica Latinoamericana, (39), pp. 104114.

MAHECHA, G. (2008). Parábolas en clave latinoamericana (y algo irreverente). Aportes Biblicos, (6 y 7). San José: Editorial Sebila, pp. 7-50.

MíGUEZ, N. (1995). Contexto sociocultural de Palestina. Revista de Interpretación Biblica Latinoamericana, (22), pp. 21-31.

MíGUEZ, N. (2004). El reino de Dios y su justicia. La parábola de los obreros de la viña, En Sánchez Cetina, E. (Ed.). Enseñaba por parábolas. Estudio del género "parábola" en la Biblia. San José (Costa Rica): Sociedades Bíblicas Unidas.

PIKETTY, T. (2014). El capital en el siglo XXI. Bogotá: Ediciones Fondo de Cultura Económica de Colombia, Ltda.

RODRÍGUEZ RODRÍGUEZ, J. (2013). Luz y oscuridad en el Nuevo Testamento: estudio terminológico. 420 p. Tesis. Departamento de Filología Clásica. Universidad de Murcia. Murcia, España.

SCHWANTES, M. (1989). Pueblo liberado Tierra rescatada. Cuenca (Ecuador): EDICAY.

SIERRA PRAELI, Y. (2019, 30 de julio). América Latina: la región con más asesinatos de defensores ambientales en el 2018. Mongabay Latam - Periodismo ambiental independiente. Disponible en: https: / / es.mongabay.com/2019/07/ america-latina-asesinatos-defensores-ambientales-2018-informe/. Visitado el: 01 ago. 2019.

STEGEMANN, E. W. \& STEGEMANN, W. (2001). Historia social del cristianismo primitivo. Navarra: Editorial Verbo Divino.

TAMEZ, E. (1993). Contra toda condena. La justificación por la fe desde los excluidos. $2^{\mathrm{a}}$. Edición. San José: Editorial DEI.

VAAGE, L. (1997). Jesús-Economista en el Evangelio de Mateo. Revista de Interpretación Biblica Latinoamericana, (27), pp. 112-128. 